\title{
Exosomes neutralize synaptic-plasticity-disrupting activity of $A \beta$ assemblies in vivo
}

\author{
Kyongman An', Igor Klyubin², Youngkyu Kim³ ${ }^{3}$, Jung Hoon Jung ${ }^{1}$, Alexandra J Mably ${ }^{4,5}$, Sean T O'Dowd ${ }^{5,6}$, \\ Timothy Lynch ${ }^{6}$, Daniel Kanmert ${ }^{4}$, Cynthia A Lemere ${ }^{4}$, Gina M Finan ${ }^{7}$, Joon Won Park ${ }^{3}$, Tae-Wan Kim, \\ Dominic M Walsh ${ }^{4}$, Michael J Rowan ${ }^{2}$ and Joung-Hun Kim ${ }^{1 *}$
}

\begin{abstract}
Background: Exosomes, small extracellular vesicles of endosomal origin, have been suggested to be involved in both the metabolism and aggregation of Alzheimer's disease (AD)-associated amyloid $\beta$-protein (A $\beta$ ). Despite their ubiquitous presence and the inclusion of components which can potentially interact with $A \beta$, the role of exosomes in regulating synaptic dysfunction induced by $A \beta$ has not been explored.

Results: We here provide in vivo evidence that exosomes derived from N2a cells or human cerebrospinal fluid can abrogate the synaptic-plasticity-disrupting activity of both synthetic and AD brain-derived AB. Mechanistically, this effect involves sequestration of synaptotoxic $A \beta$ assemblies by exosomal surface proteins such as $\operatorname{Pr} P^{C}$ rather than $A \beta$ proteolysis.
\end{abstract}

Conclusions: These data suggest that exosomes can counteract the inhibitory action of $A \beta$, which contributes to perpetual capability for synaptic plasticity.

Keywords: Alzheimer's disease, A $\beta$, Exosomes, Synaptic plasticity, PrPC

\section{Background}

Alzheimer's disease $(\mathrm{AD})$ is characterized by progressive cognitive decline [1,2]. Accumulating evidence has attributed this deficit in the cognitive capacity of patients and the potentially responsible failure in neural circuits to an increased amount of amyloid $\beta$-protein $(A \beta)$, particularly soluble $A \beta$ oligomers rather than fibrils [3]. To examine the mechanisms that underlie the synaptic dysfunction caused by $A \beta$ oligomers, several laboratories have utilized a cellular correlate of learning and memory long-term potentiation (LTP) - and have studied the effectiveness of different forms of soluble $A \beta$ preparations including $A \beta$-derived diffusible ligands (ADDLs) and $A D$ brain-derived $A \beta$ [4-7]. As $A \beta$ oligomers appear to execute their deleterious activities (i.e., LTP impairment) by binding to their putative receptors such as p75 neurotrophin receptor, insulin receptor, and cellular prion protein $\left(\operatorname{PrP}^{\mathrm{C}}\right)[4,7-9], \mathrm{A} \beta$ assemblies or their receptors have been

\footnotetext{
* Correspondence: joungkim@postech.ac.kr

'Department of Life Sciences, Pohang University of Science and Technology (POSTECH), Pohang, Gyungbuk 790-784, Korea

Full list of author information is available at the end of the article
}

targeted to develop effective therapeutic strategies $[6,10,11]$. Despite enormous efforts, however, the molecular identity and importance of intrinsic extracellular factors for regulating the activities of $A \beta$ oligomers are still poorly understood.

In this study, we focused on one class of extracellular vesicles, exosomes, as a potential regulator of $A \beta$ and its effects on synaptic plasticity in vivo. Exosomes are small (30 - $100 \mathrm{~nm}$ diameter) membranous vesicles that are secreted naturally into the extracellular space upon fusion of multivesicular bodies with the plasma membrane [12]. Although exosomes have been proposed to exert multiple physiological roles [13] and are also known to contain machinery to synthesize, degrade and induce aggregation of $A \beta$ [14-16], whether these factors in exosomes increase or decrease the deleterious actions of $A \beta$ is a matter of debate [15-18].

Direct assessment of the effect of exosomes on the activity of synaptotoxic $A \beta$ has been impeded by the difficulty in controlling their levels in vivo. Here, we have manipulated the concentration of exosomes in the brain by infusing exosomes intracerebroventricularly (i.c.v.) and 
then examined their effect on $\mathrm{A} \beta$-mediated impairment of synaptic plasticity. We find that exosomes neutralize the synaptic-plasticity disrupting activities of $\mathrm{A} \beta$ in vivo, and also show that these effects are primarily the result of the sequestration of $\mathrm{A} \beta$ oligomers via exosomal surface proteins such as $\operatorname{PrP}^{\mathrm{C}}$. The potential relevance of our findings to $\mathrm{AD}$ is underscored by our observation that exosomes from human cerebrospinal fluid (CSF) prevent the impairment of LTP that is mediated by $A \beta$ derived from $A D$ brain extracts.

\section{Results}

\section{Exosomes attenuated ADDL-mediated LTP inhibition}

We investigated whether exosomes affect A $\beta$-induced LTP impairment in the CA1 region of the dorsal hippocampus in vivo. We used ADDLs [5] prepared from synthetic $A \beta_{1-42}$ and exosomes isolated from the conditioned media of cultured N2a neuroblastoma cells (Figure 1). On SDS-PAGE, ADDLs yielded 3 bands which migrated with molecular weights of $\sim 4$ (monomer), $\sim 12$ (trimer) and 16 (tetramer) $\mathrm{kDa}$ (Figure 1A). By dynamic light scattering (DLS), ADDLs contained a mixture of species with hydrodynamic radii $\left(\mathrm{R}_{H}\right)$ ranging from $\sim 10$ to $30 \mathrm{~nm}$ (Figure $1 \mathrm{~B}$ ), but by atomic force microscopy (AFM) only small (3 $6 \mathrm{~nm}$ ) globular structures were detected (Figure 1C, D).
The apparent size discrepancy for the $A \beta$ species present in our ADDL preparation is likely to result from technical limits of the used methods. Specifically, since SDS-PAGE is highly denaturing, it might not be suitable for determination of native sizes of $A \beta$ assembly, but could be used to distinguish the SDS-stable forms from labile $A \beta$ species. While AFM could be used to detect oligomeric forms of $\mathrm{A} \beta$, certain assemblies would not adhere to mica well enough and as a result, were not detected. Nonetheless, our characterization of ADDLs revealed the presence of a heterogeneous mixture of different $A \beta$ species, some of which were at least partially stable in SDS and which existed as small globular structures of $3-6 \mathrm{~nm}[5,19]$. To prepare exosome fractions, we had excluded plasma membrane-derived fragments and other non-exosomal vesicles through the optimized procedures [20]. Contrasting to the vesicles originated from Golgi body that float at 1.05 to $1.12 \mathrm{~g} / \mathrm{ml}$ and endoplasmic reticulum-derived vesicles at 1.18 to $1.25 \mathrm{~g} / \mathrm{ml}$, exosomes are the only vesicles sizing $30 \sim 100 \mathrm{~nm}$ and gradient density ranging $1.13 \sim$ $1.19 \mathrm{~g} / \mathrm{ml}$ (Figure 1E) [12,20]. Exosomes are further defined by their expression of marker proteins such as Flotillin-1, Alix or $\operatorname{PrP}^{C}$ that are highly enriched in the exosomal fractions (Figure 1E), their ultrastructure and size (Figure 1F, G) [12]. Altogether, we verified that
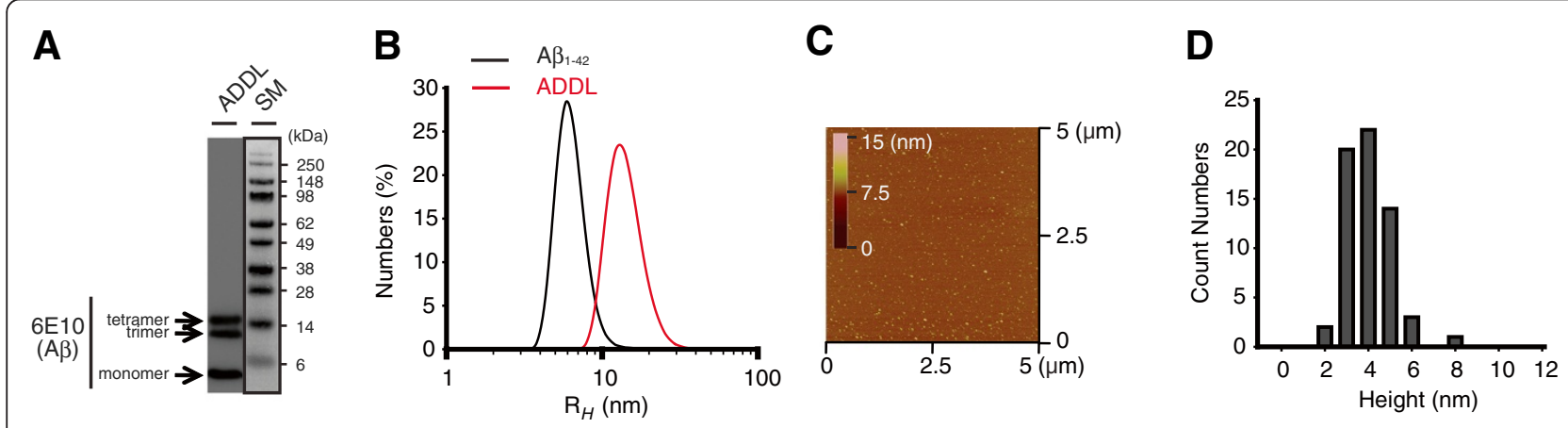

E

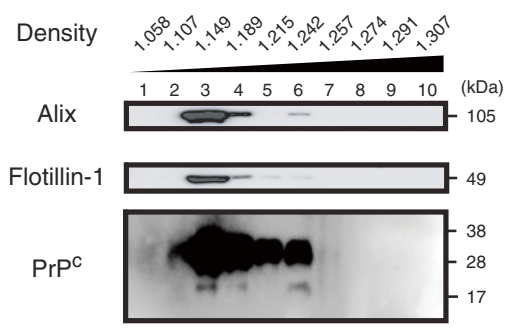

F

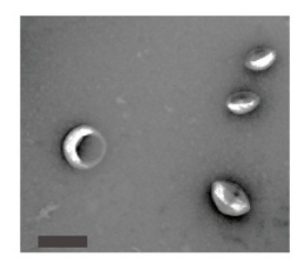

G

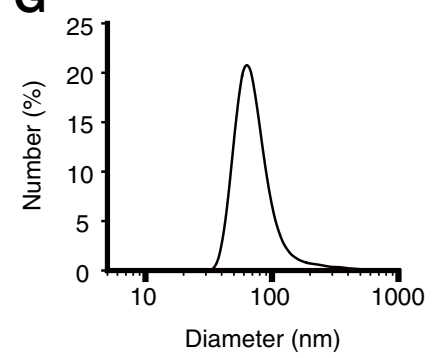

Figure 1 Characterization of ADDLs and exosomes used for biochemical and physiological experiments. (A) ADDLs were analyzed by Western blotting using 6E10. SM, size markers (kDa). (B) DLS particle distribution analysis of ADDLs (red line) (14.3 $\pm 1.1 \mathrm{~nm})$ and $A \beta_{1-42}$ freshly dissolved in $10 \mathrm{mM} \mathrm{NaOH}$ (black line) $\left(6.4 \pm 0.3 \mathrm{~nm}\right.$ ) was expressed as hydrodynamic radii $\left(R_{H}\right)$. (C) A tapping AFM mode image of ADDLs (X-Y, $5 \times 5 \mu \mathrm{m}$ with an inset displaying a z-range in color from 0 to $15 \mathrm{~nm}$ ). (D) By AFM, only small $(3-6 \mathrm{~nm})$ globular structures were detected. (E) Exosomes isolated from the conditioned medium of N2a cells had their density $1.13 \mathrm{~g} / \mathrm{ml}$ to $1.19 \mathrm{~g} / \mathrm{ml}$, and contained the exosomal marker proteins Alix, Flotilin-1 and PrPC Multiple (non-, mono- or di-) glycosylated PrPc proteins were detected between $20 \sim 35$ kDa on SDS-PAGE. (F) By EM, exosomes appeared as closed vesicles of 30-120 nm in diameter (Scale bar: $100 \mathrm{~nm}$ ), (G) a size range that agreed with that measured by DLS. 
our procedures were able to yield relatively pure exosomes $[12,20]$.

In agreement with prior reports [5], high-frequency stimulation (HFS) failed to trigger robust LTP in anesthetized rats that had received i.c.v. injection of ADDLs (PBS + ADDL, $105 \pm 6 \%, n=4$ vs. PBS + PBS, $166 \pm 10 \%$, $\mathrm{n}=4$ at $3 \mathrm{~h}$ post-HFS, $P<0.001$, one-way ANOVA with post hoc Tukey; Figure 2A). Somewhat unexpectedly, prior infusion of $4 \mu \mathrm{g}$ exosomes markedly attenuated the synaptic-plasticity-disrupting action of ADDLs. Indeed, despite the administration of ADDLs, HFS now induced robust LTP that was comparable to the control levels and which remained stable for more than $3 \mathrm{~h}$ (Exo + ADDL, $152 \pm 6 \%, \mathrm{n}=5, P<0.01$ vs. PBS + ADDL; $P>0.4$ vs. PBS + PBS, one-way ANOVA with post hoc Tukey;
Figure 2A). Of note, the effect of exosomes against ADDL-induced LTP inhibition was largely dependent upon the amount of exosomes, producing a significant effect when $4 \mu \mathrm{g}$ or more was infused (Figure 2B). Unless otherwise specified, therefore, we used $4 \mu \mathrm{g}$ exosomes in the subsequent studies. In this condition, however, neither exosomes nor ADDLs significantly affected baseline synaptic transmission (Figure 2C). Exosomes might exert this protective effect by enhancing LTP per se, and/or functionally counteract the plasticity-disrupting effect of ADDLs. When we examined the ability of exosomes to convert decremental LTP into stable LTP or boost control LTP, however, we did not detect any significant difference on weak HFS-induced decremental LTP (PBS, $106 \pm 7 \%$, $\mathrm{n}=5$ vs. Exo, $117 \pm 6 \%, \mathrm{n}=4, P>0.3$, unpaired t-test;

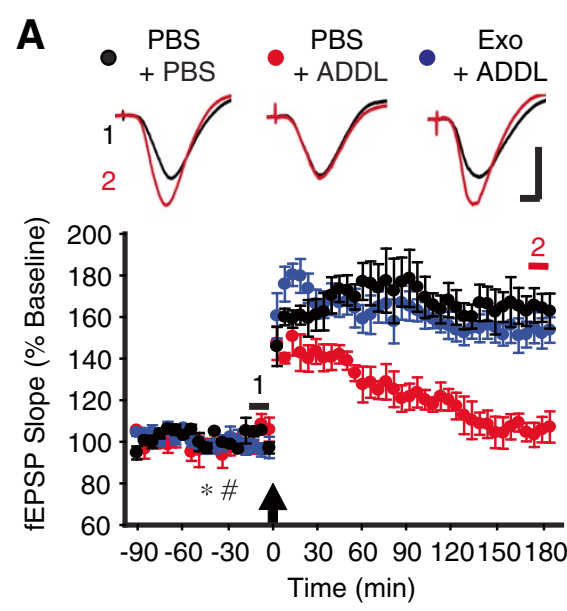

B

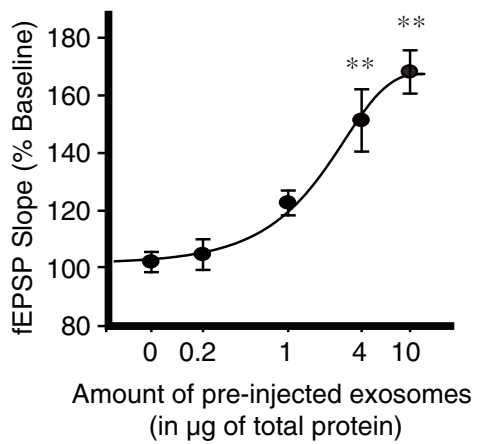

C
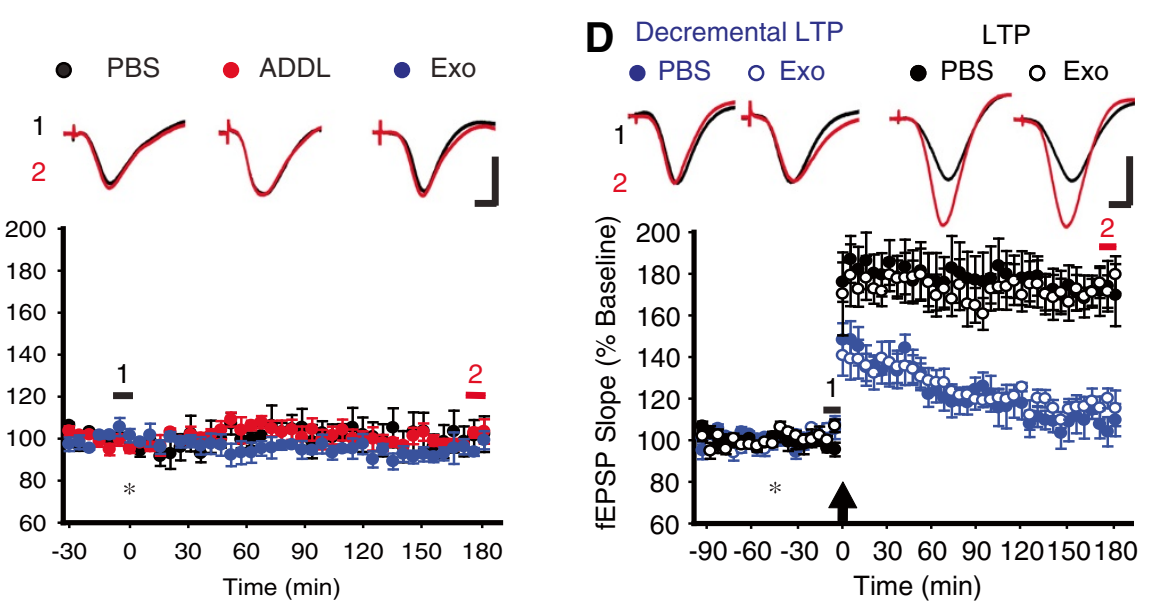

Figure 2 Exosomes abrogate ADDL-mediated disruption of LTP. (A) Prior infusion of exosomes (4 $\mu \mathrm{g}$ in $5 \mu$ l, asterisk) prevented ADDLs (10 pmol in $5 \mu \mathrm{l}$, hash) inhibiting LTP. Animals received sequential injections of exosomes and ADDLs before the application of HFS (arrow). Insets show representative traces at the color-matched time points. Calibrations: $1.5 \mathrm{mV}$ and $10 \mathrm{~ms}$ for all traces. (B) Dose-dependent protective effect of exosomes against ADDL-mediated disruption of LTP $(0 \mu \mathrm{g}$ Exo $+\mathrm{ADDL}, 100 \pm 3 \%, \mathrm{n}=5 ; 0.2 \mu \mathrm{g}$ Exo $+\mathrm{ADDL}, 105 \pm 5 \%, \mathrm{n}=4 ; 1 \mu \mathrm{g}$ Exo $+\mathrm{ADDL}$, $123 \pm 5 \%, n=4 ; 4 \mu \mathrm{g}$ EXo $+A D D L, 151 \pm 10 \%, n=6 ; 10 \mu \mathrm{g}$ EXo $+A D D L, 168 \pm 9 \%, n=4)$. Statistical significance was expressed as $* *, P<0.01$ comparing to control group injected with $0 \mu \mathrm{g}$ Exo + ADDL. (C) Neither exosomes nor ADDLs ( $5 \mu \mathrm{l}$, asterisk) affected baseline excitatory synaptic transmission in the $C A 1$ area in vivo (PBS, $n=4 ; A D D L, n=5 ;$ Exo, $n=4)$. (D) Exosomes $(4 \mu \mathrm{g}$ in $5 \mu$, asterisk) did not enhance decremental or standard LTP. An arrow indicates the time point of application of either weak HFS for decremental LTP or HFS for standard LTP, respectively. Insets and calibrations as in A. Error bars, \pm SEM. 
Figure 2D) or standard HFS-induced LTP (PBS, $172 \pm$ $13 \%, \mathrm{n}=5$ vs. Exo, $175 \pm 8 \%, \mathrm{n}=4, P>0.8$, unpaired t-test; Figure 2D). Thus, direct facilitatory effects on the magnitude of LTP are unlikely to account for the capability of exosomes to rapidly abrogate the inhibitory effects of ADDLs.

\section{ADDLs are sequestered on the surface of exosomes}

To address possible mechanisms underlying the protective action of exosomes against ADDL-induced LTP inhibition, we first examined whether exosomes degrade $\mathrm{A} \beta$, which could abrogate the plasticity-disrupting effect. When we incubated ADDLs with exosomes in the same ratio used for LTP experiments, this resulted in a loss of the $\mathrm{A} \beta$ species that migrated at $\sim 4 \mathrm{kDa}$ (monomer) on SDS-PAGE $(32 \pm 13 \%, P<0.01, \mathrm{n}=5$, Mann-Whitney $U$ test; Figure $3 \mathrm{~A})$. Unlike $\mathrm{A} \beta$ monomer, $\mathrm{A} \beta$ oligomers were largely unaffected by the incubation with exosomes $(\sim 12 \mathrm{kDa} \mathrm{A} \beta, 96 \pm 10 \%, P>0.5 ; \sim 16 \mathrm{kDa} \mathrm{A} \beta, 97 \pm 5 \%$, $P>0.05, \mathrm{n}=5$, Mann-Whitney $U$ test; Figure $3 \mathrm{~A}$ ), indicating that exosomes did not effectively degrade $A \beta$ oligomers at least over the time course of our experiments. Although the reason for the loss of $A \beta$ monomer is unclear, it could result from the degradation of authentic A $\beta$ monomer by exosomal proteases such as insulindegrading enzyme (IDE) [15,21]. However, since monomeric A $\beta$ does not inhibit LTP [22] and IDE is not believed to degrade plasticity-disrupting $A \beta$ oligomers [23], such degradation would not be expected to contribute to the rescue of the ADDL-mediated block of LTP.

On the other hand, exosomes might decrease free $A \beta$ oligomers available by shifting free $A \beta$ to the exosomebound $A \beta$. We examined this possibility by incubating ADDLs with exosomes and then physically separating (by centrifugation) exosomes from unbound $A \beta$. A major proportion of $A \beta$ oligomers co-migrated with the exosomes that were readily pelleted with ultracentrifugation whereas only a small fraction of free ADDLs remained in the supernatant fraction (mean \% of pelleted $\mathrm{A} \beta$ relative to total $\mathrm{A} \beta$ : PBS $+\mathrm{ADDL}, 7 \pm 2 \%$ vs. Exo + ADDL, $82 \pm 7 \%, P<0.05, \mathrm{n}=3$, Mann-Whitney $U$ test; Figure $3 \mathrm{~B})$. However, this could have resulted potentially from $A \beta$ assemblies that were simply pelleted to the exosomecontaining fraction after being aggregated by exosomes [16], rather than being directly bound to exosomes. Therefore, we have corroborated the direct binding of $\mathrm{A} \beta$ assemblies and exosomes by directly pulling down the exosome-bound $A \beta$ after their in vitro incubation (Additional file 1: Figure S1), which argues against the possibility.

To elucidate the possible fate of $A \beta$ oligomers following binding onto exosomes, we have developed a partial trypsinization protocol to degrade only proteins on the outside of exosomes (see Methods for detailed infor-
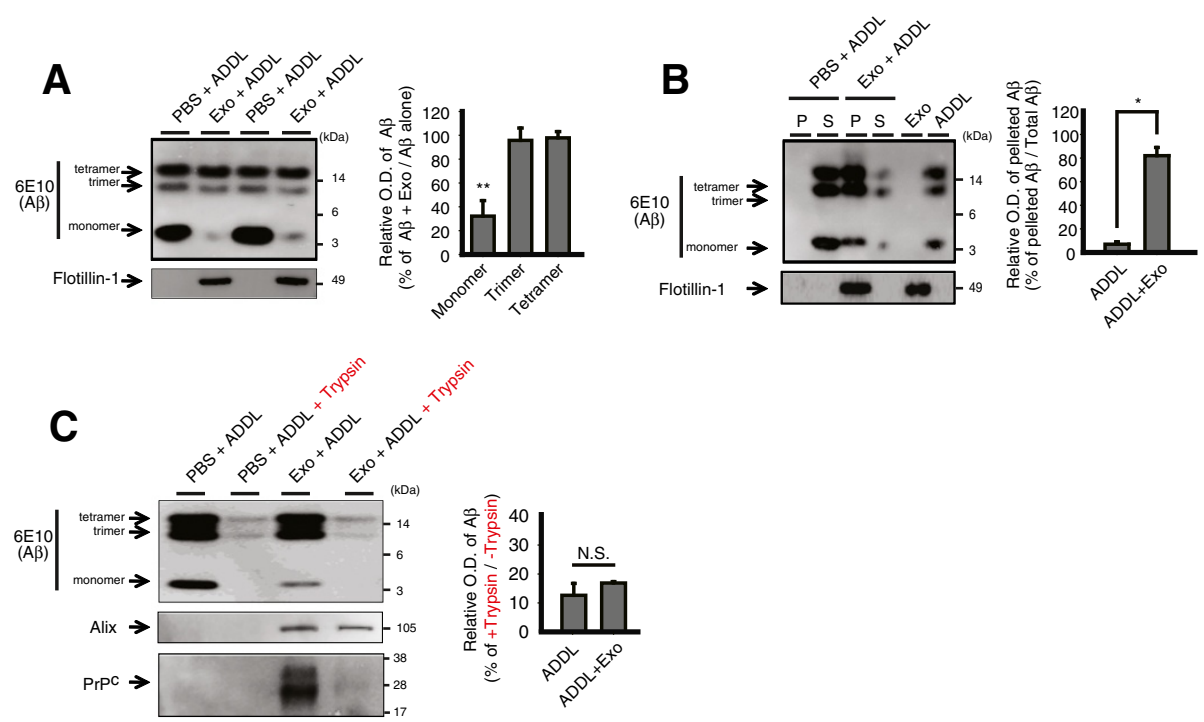

Figure 3 ADDLs bound to exosomes. (A) Immunoblots of ADDLs after incubation either with PBS or exosomes (left top). Exosomes present in each lane were verified with Flotillin-1 (left bottom). Right, relative optical density (O.D.) of A $\beta$ species. (B) Immunoblot results of in vitro binding assay of $A \beta$ and exosomes (left top). Either exosomes or ADDLs alone were loaded as controls. Left bottom, exosomes were also verified with an exosomal marker Flotillin-1 (P, pellet; S, supernatant). Right, relative O.D. of pelleted A $\beta$. (C) Exosome-bound ADDLs remained accessible to digestion by trypsin (left top). Limited proteolysis with trypsin resulted in cleavage of exosomal surface protein PrPC, but not the intraluminal protein Alix (left, middle and bottom). Very low amount of ADDLs remained after trypsin treatment and the levels of which were similar irrespective of the presence or absence of exosomes (right, relative O.D. of A $\beta$ ). Error bars, \pm SEM. Statistical significance was expressed as $*, P<0.05 ;{ }^{* *}, P<0.01$. 
mation) and applied this method after the incubation of exosomes and ADDLs. If ADDLs were internalized into exosomes, the resultant ADDLs residing in the lumen of exosomes should be resistant to trypsin, which would likely leave more ADDLs remaining after the treatment of trypsin. Inconsistent with this notion, the remaining amount of ADDLs did not differ in the absence and presence of exosomes (\% of remaining $\mathrm{A} \beta$ after trypsinization: PBS + ADDL, $12 \pm 4 \%$ vs. Exo + ADDL, $17 \pm 1 \%$; $P=0.51, \mathrm{n}=3$, Mann-Whitney $U$ test; Figure $3 \mathrm{C}$ ). Therefore, a major proportion of ADDLs remains on the surface of exosomes even after binding to exosomes in the time frame we examined, rather than being internalized into exosomes. Collectively, it is reasonable to speculate that the protective effect of exosomes against ADDLinduced LTP impairment arises from sequestering and immobilization of $A \beta$ oligomers at the surface of exosomes.
Exosomal surface proteins including $\operatorname{PrP}^{C}$ are required for the protective role of exosomes against $A \beta$

To further investigate the direct interaction of ADDLs with exosomes, we used trypsin in a mild condition (see Methods for details) to assess whether exosomal surface proteins were required for ADDL-neutralizing activity. The partial trypsinization efficiently removed the exosomal surface proteins while leaving the luminal protein intact (Figure 4A), and without affecting the integrity of exosomes (Figure 4B, C). Importantly, the trypsinized exosomes were no longer capable of rescuing the ADDL-mediated block of LTP (T' ${ }^{-}$Exo + ADDL, $161 \pm$ 9\%, $\mathrm{n}=5$ vs. $\mathrm{T}^{+}$Exo $+\mathrm{ADDL}, 107 \pm 6 \%, \mathrm{n}=4, P<0.01$, one-way ANOVA with post hoc Tukey; Figure 4D), and did not alter either LTP per se $\left(\mathrm{T}^{+}\right.$Exo + PBS, $170 \pm 7 \%$, $\mathrm{n}=4, P>0.9$ compared to PBS + PBS, one-way ANOVA with post hoc Tukey; Figure 4D) or baseline synaptic transmission (Figure 4E). In agreement with the LTP
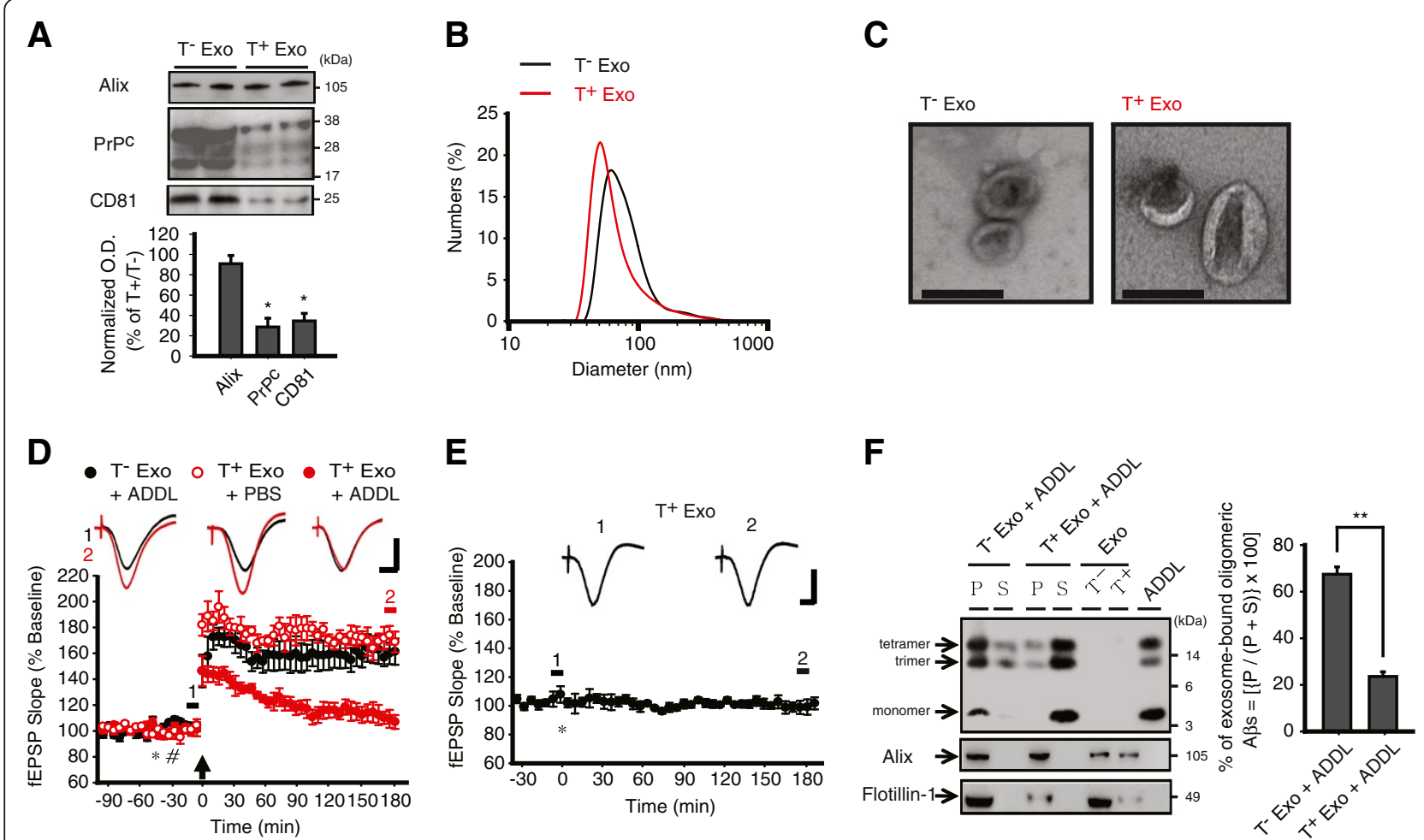

Figure 4 Exosomal surface proteins are essential for the protective role of exosomes against the synaptic-plasticity-disrupting action of ADDLs. (A) Trypsinization ( $T^{+}$) was effective in removing surface proteins ( $\operatorname{PrP}^{C}$ and $C D 81$ ), but not luminal protein (Alix) of N2a cell-derived exosomes when compared to non-trypsinized $(T)$ control. Top, representative blots and bottom, normalized mean O.D. of immunoblots, $n=5$. (B) Trypsinized exosomes ( $T^{+}$Exo, red line) had similar sizes $\left(74 \pm 3 \mathrm{~nm}\right.$ ), compared with those of non-trypsinized exosomes ( $T^{-}$Exo, black line) $(83 \pm 7 \mathrm{~nm}, P>0.05, \mathrm{n}=3)$, as measured by DLS. (C) By EM, the structure and size of $\mathrm{T}^{+}$Exo were indistinguishable from $T$ Exo (Scale bar: $\left.100 \mathrm{~nm}\right)$. (D) T Exo ( $5 \mu \mathrm{l}$, asterisk) was unable to prevent the plasticity-disrupting-activity of ADDLs (10 pmol in $5 \mu \mathrm{l}$, hash), but which can be neutralized by T Exo. An arrow indicates HFS application and insets show representative traces at the color-matched time points. Calibration: $1.5 \mathrm{mV}$ and 10 ms. (E) Lack of effect of i.c.v. injection (asterisk) of $\mathrm{T}^{+}$Exo $(n=4)$ on the stability of fEPSP recordings. (F) Comparing to $T^{-}$Exo, $T^{+}$Exo showed a reduced ability to sequester $A D D L$ s. Left panel: representative immunoblot using antibodies against $A \beta(6 E 10)$, Alix and Flotillin-1 (P, pellet; $S$, supernatant). Right panel: mean $\%$ of $\sim 12$ and $16 \mathrm{kDa} A \beta$ bound to exosomes (P) relative to total $\sim 12$ and $16 \mathrm{kDa} A \beta(P+S)$. Error bars, \pm SEM. Statistical significance was expressed as ${ }^{*}, P<0.05 ;{ }^{*}, P<0.01$. 
results, trypsinized exosomes bound only a smaller fraction of $\mathrm{A} \beta$ oligomers compared to non-trypsinized exosomes ( $\mathrm{T}^{-}$Exo $+\mathrm{ADDL}, 67 \pm 3 \%$ vs. $\mathrm{T}^{+}$Exo $+\mathrm{ADDL}, 24 \pm$ $2 \%, P<0.01, \mathrm{n}=5$, Mann-Whitney $U$ test; Figure $4 \mathrm{~F}$ ). These data indicate that surface proteins of exosomes are required for the sequestration of synaptotoxic $A \beta$ assemblies, which is consistent with prior reports that binding of $A \beta$ oligomers to neuronal membranes is mediated by trypsin-sensitive molecules [5].

$\mathrm{A} \beta$ oligomers bind to $\operatorname{PrP}^{\mathrm{C}}$, a cell membrane-bound glycoprotein that express abundantly in the central nervous system, specifically and with high affinity [6,7,24]; $\mathrm{PrP}^{\mathrm{C}}$ was also known to be expressed at high levels on exosomes $[25,26]$. Thus, we sought to examine whether exosomal $\mathrm{PrP}^{\mathrm{C}}$ contributes to the sequestration of ADDLs by exosomes. To this end, we prepared exosomes from either Prnp $^{+/+}$(wild-type, PrP ${ }^{\mathrm{C}} \mathrm{WT}$ ) or Prnp ${ }^{-/-}\left(\mathrm{PrP}^{\mathrm{C}}\right.$ knockout, $\operatorname{PrP}^{\mathrm{C}} \mathrm{KO}$ ) hippocampal cell lines [27] (Figure 5A-C).
Because we injected exogenously $\mathrm{PrP}^{\mathrm{C}} \mathrm{WT}$ or $\mathrm{KO}$ exosomes through i.c.v. to wild type rat throughout the study, acute infusion of these exosomes into the brain can change only $\operatorname{PrP}^{C}$ of extracellular exosomes alone, but not neuronal $\mathrm{PrP}^{\mathrm{C}}$ level of subject animals. Intriguingly, the effectiveness of $\mathrm{PrP}^{\mathrm{C}} \mathrm{KO}$ exosomes in preventing ADDL-induced LTP inhibition was significantly reduced compared with that of WT exosomes (WT Exo + ADDL, $159 \pm 5 \%$, $\mathrm{n}=6$, $P<0.001$ vs. $\mathrm{PBS}+\mathrm{ADDL}, 101 \pm 5 \%, \mathrm{n}=6 ; \mathrm{P}<0.05$ vs. $\mathrm{KO}$ Exo + ADDL, $129 \pm 3 \%, \mathrm{n}=5$, one-way ANOVA with post hoc Tukey; Figure 5D, E) and the binding of $\mathrm{A} \beta$ oligomers to $\operatorname{PrP}^{\mathrm{C}} \mathrm{KO}$ exosomes was also significantly decreased compared to WT exosomes (WT Exo + ADDL, $70 \pm 2 \%$ vs. KO Exo + ADDL, $45 \pm 5 \% ; \quad P<0.01, \mathrm{n}=5$, MannWhitney $U$ test; Figure 5F). The finding that knock-out of exosomal $\mathrm{PrP}^{\mathrm{C}}$ reduced ADDL binding and the exosomeinduced rescue of LTP to a similar extent suggests that both effects are mediated, at least in part, through $\operatorname{PrP}^{\mathrm{C}}$.

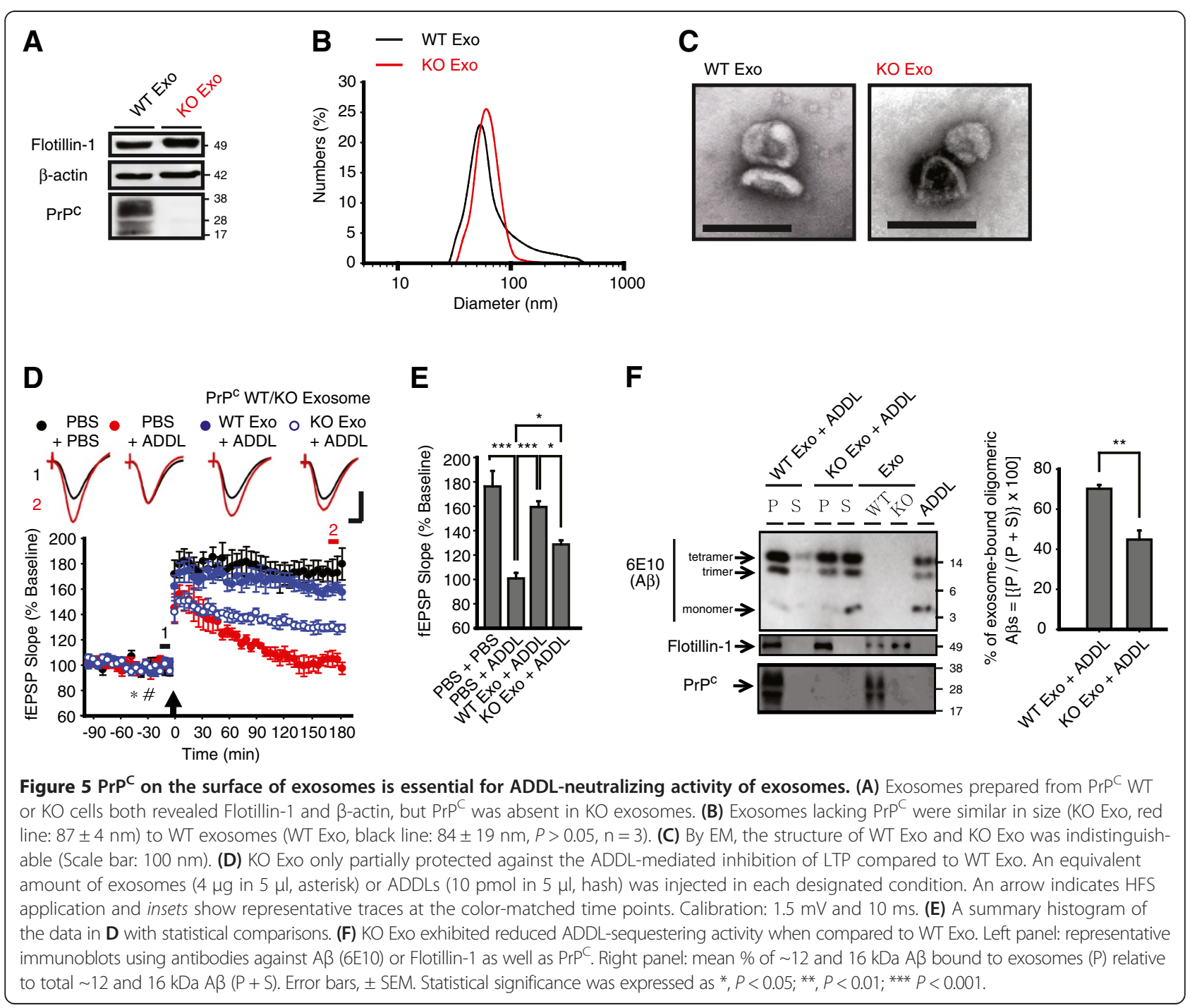


Both N2a cell- and human CSF-derived exosomes prevent $A D$ brain-derived $A \beta$ from affecting LTP

Because it remains unknown whether $A \beta$ assemblies formed in vitro accurately represent $A \beta$ species found in human brain, we investigated if exosomes could prevent the disruptive activity of the most disease-relevant form of $A \beta, A \beta$ extracted from AD brain. Aqueous extracts of $\mathrm{AD}$ brain contained $\mathrm{A} \beta$ species which migrated on SDSPAGE as monomers and dimers (Figure 6A) and potently inhibited LTP (Figure 6B, E and F). Consistent with our previous reports [11], this inhibition of LTP was attributable to $A \beta$ but not any other components of the $\mathrm{AD}$ extract since specific removal of $\mathrm{A} \beta$ reversed this effect, whereas mock-immunodepletion did not (PBS +
$\mathrm{AD}-\mathrm{A} \beta^{+}, 110 \pm 9 \%, \mathrm{n}=5$ vs. $\mathrm{PBS}+\mathrm{AD}-\mathrm{A} \beta^{-}, 176 \pm 7 \%, \mathrm{n}=5$, $P<0.001$, one-way ANOVA with post hoc Tukey; Figure 6B, F). Importantly, the i.c.v. infusion of N2a cell-derived exosomes fully abrogated the inhibitory effect of $A \beta$-containing $\mathrm{AD}$ brain extracts (Exo $+\mathrm{AD}-\mathrm{A} \beta^{+}, 175 \pm 9 \%, \mathrm{n}=7, P<0.001$ vs. $\mathrm{PBS}+\mathrm{AD}-\mathrm{A} \beta^{+}$, one-way ANOVA with post hoc Tukey; Figure $6 \mathrm{~B}, \mathrm{C}$ and $\mathrm{F}$ ), but did not affect LTP induced in the presence of $\mathrm{A} \beta$-immunodepleted $\mathrm{AD}$ brain extracts (Exo + $\mathrm{AD}-\mathrm{A} \beta^{-}, 179 \pm 10 \%, \mathrm{n}=5, P>0.05$ vs. $\mathrm{PBS}+\mathrm{AD}-\mathrm{A} \beta^{-}$, oneway ANOVA with post hoc Tukey; Figure 6B, C and F).

Next, we tested whether human brain-derived exosomes could also neutralize plasticity-disrupting forms of $A \beta$. To do this, we isolated exosomes from the CSF of healthy volunteers (Figure 6D). Due to the limited amount of CSF

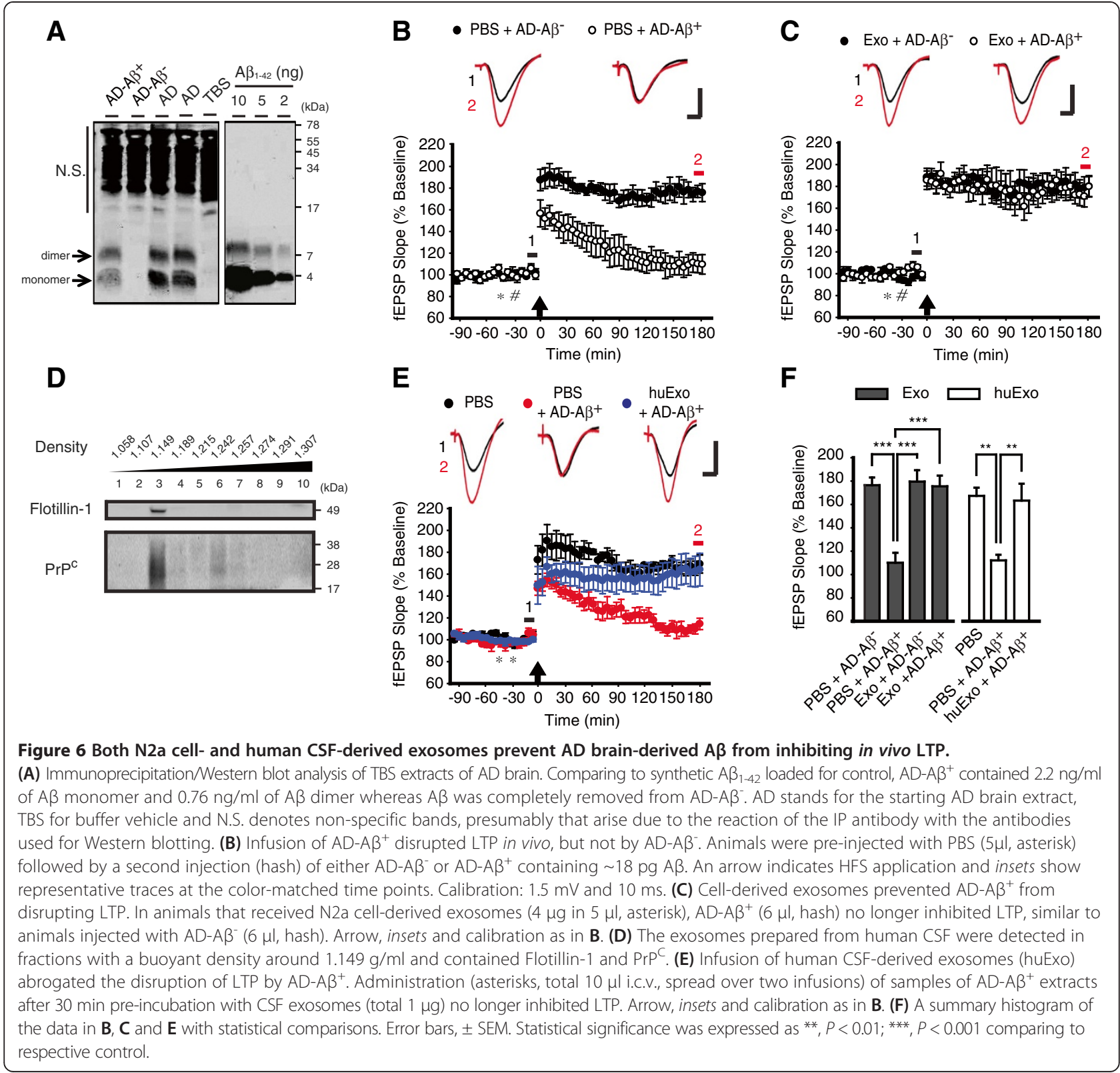


exosomes available, we modified our experimental paradigm to pre-incubating CSF exosomes with AD brain extracts and then injecting the mixture before HFS as previously used [10]. When CSF exosomes $(1 \mu \mathrm{g})$ were pre-incubated with AD brain extracts, normal LTP was induced whereas injection of the same $A \beta$-containing $A D$ brain extracts without exosomes consistently inhibited LTP (huExo $+\mathrm{AD}-\mathrm{A} \beta^{+}, 163 \pm 14 \%, \mathrm{n}=5, P>0.9$ vs. PBS, $167 \pm 7 \%, \mathrm{n}=4 ; P<0.01$ vs. $\mathrm{PBS}+\mathrm{AD}-\mathrm{A} \beta^{+}, 112 \pm 5 \%, \mathrm{n}=$ 5 , one-way ANOVA with post hoc Tukey; Figure 6E, F). These results demonstrate that CSF-derived exosomes can also protect LTP against the plasticity-disrupting activity of $\mathrm{AD}$ brain-derived $\mathrm{A} \beta$.

\section{Discussion}

Although cellular functions of exosomes in nervous system are not completely understood, previous studies have provided evidence that exosomes can participate in paracrine delivery of biologically active and infectious materials such as $A \beta, \operatorname{PrP}^{C}$ and $\alpha$-synuclein [28-31]. It was also suggested that lipid components or IDE on the surface of exosomes were involved in the regulation of $\mathrm{A} \beta$ by activating fibrillization or proteolysis $[15,16,32,33]$. Although those reports had suggested the potential interaction between $A \beta$ and exosomes, however, the physiological role of exosomes remains largely unknown particularly for $A \beta$-induced synaptotoxicity $[15,16,18]$. This would stem from the fact that the controlled manipulation of the levels of exosomes in the brain is very difficult and thus the direct assessment of the putative roles that exosomes exert has been hampered. Using an infusion paradigm, we discovered that addition of exogenous exosomes into brain can abrogate the synapticplasticity-disrupting activities of $A \beta$, most likely through direct sequestration of $A \beta$ oligomers.

Whereas it is generally postulated that synaptic failure in $A D$ is caused by soluble $A \beta$ assemblies, the molecular mechanisms whereby $A \beta$ assemblies are formed and maintained for AD pathogenesis remains unclear yet [4]. Although we could not fully identify the molecular identity of synaptotoxic $A \beta$ assemblies, we confirmed that our $A \beta$ preparations from synthetic $A \beta_{1-42}$ peptide or AD brain extraction can effectively inhibit synaptic plasticity in vivo $[5,6,11,34]$, which validated the efficacy of the used experimental conditions. Furthermore, multiple characterization assays that we used revealed the presence of a heterogeneous mixture of different sized $A \beta$ species and also relatively pure exosomal preparation, consistent with previous reports $[5,12,19,20]$. In addition to the protective effect of exosomes against synaptotoxic activity of ADDLs, we found that exosomes were able to ameliorate the plasticity-disrupting activity of the most pathophysiologically-relevant form of $A \beta, A \beta$ extracted from $\mathrm{AD}$ brain. Interestingly, we had to inject at least 45 ng of ADDLs and only 18 pg of $A \beta$ from $A D$ brain to produce potent inhibition of LTP. We and others have previously reported that the potency of synthetic $A \beta$ used to disrupt the memory of learned behavior or to impair LTP is usually several orders of magnitude higher than that of naturally produced $A \beta$ from the AD brain or APP expressing-cultured cell lines $[11,34,35]$. The different potency of the two $A \beta$ preparations used in the present experiments likely reflects the fact that although they contained similar concentrations of synaptic plasticity disrupting $A \beta$, other additional assemblies, that are presumed to be relatively inactive, are present in higher concentration in the ADDL preparation compared to AD brain extracts.

The protective effect of exosomes against the synapticplasticity-disrupting activity of $A \beta$ leaves the question about the underlying mechanisms. As $A \beta$ itself is a sticky protein and exosomes contain a variety of proteins and lipid components, there are several possibilities including non-specific proteolysis or sequestration such that a number of proteins, lipids, and membranous vesicles could affect A $\beta$-mediated LTP inhibition. Throughout biochemical experiments and in vivo electrophysiology, however, we demonstrate that proteolysis of $A \beta$ is unlikely account for the protective effect; rather exosomes could sequester $A \beta$ oligomer in a manner analogous to binding of neutralizing antibodies $[10,36]$. Still, we cannot directly interpret the effect of decreased $\mathrm{A} \beta$ monomer by exosomes in vivo since the effect of monomeric $A \beta$ on synaptic plasticity had been examined only on hippocampal slice and the different protocol used to induce LTP could also compound A $\beta$-induced synaptic alteration [22,37]. Over brain slices and primarily cultured neurons, $A \beta$ monomer showed protective effects on LTP and neuronal survival $[38,39]$. Therefore, the possible outcomes that chronically-decreased A $\beta$ monomer produces should be further studied. Moreover, the sequestration of $A \beta$ depends upon surface proteins of exosomes such as $\operatorname{PrP}^{\mathrm{C}}$, which supports the idea that specific involvement of exosomal surface proteins to capture or immobilize soluble $A \beta$ oligomer at exosomes. Especially, the ineffectiveness of trypsinized exosomes in neutralizing synaptotoxicity of $A \beta$ argues against the possibility of involving exosomal lipids for the exosomes' protective effect. Because we examined only the effect of exosomes in this study, the effect of other small membranous vesicles that also derive from plasma membrane or other intracellular origins on $\mathrm{A} \beta$-mediated synaptotoxicity should be verified further.

The role of $\operatorname{PrP}^{\mathrm{C}}$ as a putative receptor for $\mathrm{A} \beta$ oligomer, and its involvement in $\mathrm{A} \beta$-mediated impairment of LTP has been intensely debated [7,40-42], but there is no controversy regarding the ability of $\operatorname{PrP}^{\mathrm{C}}$ to bind $\mathrm{A} \beta$. Multiple independent studies concluded that $\operatorname{PrP}^{\mathrm{C}}$ binds $\mathrm{A} \beta$ oligomers specifically and with high affinity $[6,7,40,43-45]$. In 
this study, we detected that exosomes from $\operatorname{PrP}^{\mathrm{C}}$-deficient cells are significantly less able to protect against $A \beta$ than $\mathrm{PrP}^{\mathrm{C}}$-containing exosomes. This $\mathrm{PrP}^{\mathrm{C}}$-dependent effect of exosomes would be due to the high affinity binding of $\mathrm{A} \beta$ to $\operatorname{PrP}^{\mathrm{C}}$. Therefore, exosomes that derived from cell lines expressing mutated $\operatorname{PrP}^{\mathrm{C}}$ at the binding site for $\mathrm{A} \beta$ (95105 residues of $\operatorname{PrP}^{\mathrm{C}}$ ) could be used to further verify the function of $\operatorname{PrP}^{C}$ in detail $[7,45]$. In this study, we can use only the exosomes from "immortalized cell lines" of WT or $\operatorname{PrP}^{\mathrm{C}}$-depleted neurons due to the difficulty to collect large amount of exosomes from primarily cultured neuron or from CSF of genetically modified mice. Notably, the fact that ablation of $\operatorname{PrP}^{\mathrm{C}}$ did not completely obviate the protective effects of exosomes suggests that exosomal proteins other than $\operatorname{PrP}^{\mathrm{C}}$ might also contribute to the sequestration of toxic $A \beta$ oligomers, as consistent with previous observation that $A \beta$ binding was only partially reduced to $\operatorname{PrP}^{\mathrm{C}}$-deficient neurons [7]. To elucidate the full repertoire of candidate exosomal proteins involved in the interaction with $A \beta$ and to further understand their molecular mechanisms, further screening and functional studies will be necessary.

It might be informative to examine whether exosomes in culture medium play a protective role against the toxic effect of $A \beta$ on primarily cultured neuron. However, $A \beta$-induced deficit in synaptic plasticity normally occurs well before manifest loss of neurons in $\mathrm{AD}$ models $[2,4,46]$. To establish whether the effects of $A \beta$ and exosomes on synaptic plasticity are reflected at the level of cognition, behavioral tests determining their effect on cognitive function will be required.

In this study, we provide evidence for the neutralizing action of exosomes against A $\beta$-induced LTP impairment using both N2a cell-derived exosomes and human CSFderived exosomes. These observations raised an important question: Do endogenous exosomes normally prevent $A \beta-$ mediated impairment of synaptic plasticity? However, demonstration for effects of endogenous exosomes on $\mathrm{AD}$ pathogenesis or $\mathrm{A} \beta$-induced alteration of synaptic plasticity was very challenging due to the difficulties to modify the nature and quantity of exosomes in the brain without any side effects. For example, when we activated the recycling of endosomes to increase the release of exosomes, the manipulation might affect production and release of $A \beta$ [47]. The amount of exosomes prepared from human CSF or interstitial fluid of brain has been measured only in a few studies for its scarcity [48]. Although we were also unable to quantify the exosome content in a systematic manner due to the limited supply of fresh CSF, we did obtain approximately $8 \mu \mathrm{g}$ of exosomes from $10 \mathrm{ml}$ of human CSF following the purification steps including density gradient fractionation that normally involves considerable loss of exosomes (up to $60 \%$ of the starting amount; see ref. Tauro et al. [49]). Accordingly, we esti- mated $\sim 2 \mu \mathrm{g}$ endogenous exosomes contained in $1 \mathrm{ml}$ of human CSF as consistence with previous study [48]. Therefore, we surmise that our i.c.v. infusion of $4 \mu \mathrm{g}$ exosomes would yield $\sim 4$ times the concentration of endogenous exosomes present in rat CSF, assuming that rat CSF (ranged $500 \mu \mathrm{l}$ total; see ref. Lai et al. [50]) contained an exosome content similar to that of human CSF. Importantly, $1 \mu \mathrm{g}$ of CSF-derived exosomes exhibited a significantly protective effect when co-injected with $A \beta$-containing AD brain extracts (Figure 6). Taken together, we speculate that exosomes may protect synaptic plasticity against amyloidogenic insults in situ particularly over an extended time window. Considering studies indicating the increased release of exosomes by $2.5-4$ folds under in vitro hypoxia condition [15,51], it is very likely that this process could be occurred in pathological condition. Eventually, exosome-bound $\mathrm{A} \beta$ might be taken up by microglia for degradation in normal condition [16], or they can be the seed for the plaque formation in pathological condition [52]. The efficiency of this process may be critical in determining the onset and progression of $\mathrm{AD}$ given the causal contribution of synaptic failure to the disease and cognitive decline [2]. Since both $A \beta$ and exosomes are released from the brain in an activity-dependent manner $[53,54]$, the dynamic change of exosome concentration in brain, especially in $\mathrm{AD}$ patients, is a subject that we feel should be explored further.

\section{Conclusions}

Collectively, exosomes are able to sequester synaptotoxic $A \beta$ oligomers via surface proteins such as $\operatorname{PrP}^{C}$ and thereby rescue LTP from $A \beta$-mediated impairment in vivo. Importantly, our findings based on exosomes isolated from human CSF and $\mathrm{A} \beta$ from $\mathrm{AD}$ brain strongly indicate that the pathophysiologically relevant forms of $A \beta$ in the brain can be sequestered by exosomes. Although we were unable to quantitatively measure the change of total exosome concentration in the brain after exogenous application, at the very least we were successful in using human CSF samples to provide a reasonable and predictive window on exosome levels in the brain and thus to assess the utility of this measure as a biomarker for AD. Similarly, when we can manipulate the levels of endogenous exosomes in a more precise manner, we will be in a better position to ascertain their pathophysiological contribution to $\mathrm{AD}$ and perhaps supply exogenous exosomes or artificially engineered forms of lipid vesicles for a therapeutic benefit.

\section{Methods}

\section{Animals}

Male Wistar rats (250 - 350 g) were used for in vivo recording experiments. They were housed under a 12-hour light/dark cycle and given ad libitum access to food and water. The rats were anesthetized with urethane (ethyl 
carbamate, $1.5 \mathrm{~g} / \mathrm{kg}$, i.p.). The body temperature was maintained at $37.4-38^{\circ} \mathrm{C}$ for the duration of the experiments. All procedures for animal experiments were approved by the ethical review committee of Trinity College Dublin and the Department of Health and Children, Ireland and POSTECH (Pohang University of Science \& Technology), Korea and performed in accordance with the relevant guidelines.

\section{ADDLs preparation}

$\mathrm{A} \beta_{1-42}$ (American peptide) was dissolved in 1,1,1,3,3,3hexafluoro-2-propanol (Sigma) to a concentration of 1 $\mathrm{mM}$. The solution was allowed to evaporate for $2 \mathrm{~h}$ and then dried in a Speed Vac. The resulting film of peptide was stored at $-20^{\circ} \mathrm{C}$ or immediately resuspended in dimethyl sulfoxide (Sigma) to produce a $1 \mathrm{mM}$ solution. This solution was sonicated for $10 \mathrm{~min}$ in a sonic bath, and then diluted to $100 \mu \mathrm{M}$ in phenol red-free Ham's F12 medium (Life Technology) and incubated for $12 \mathrm{~h}$ at $4^{\circ} \mathrm{C}$. The resulting solution was then spun at 100,000 g for $1 \mathrm{~h}$ and either used immediately or stored at $-80^{\circ} \mathrm{C}$ for up to 2 weeks. Monomeric $\mathrm{A} \beta_{1-42}$ was prepared by dissolving the peptide film to $100 \mu \mathrm{M}$ in $10 \mathrm{mM} \mathrm{NaOH}$ solution ( $\mathrm{pH} 11)$.

\section{Isolation of exosomes}

$\mathrm{N} 2 \mathrm{a}$ cells were grown in exosome-depleted medium comprising 44.5\% DMEM, 44.5\% Opti-MEM with 10\% FBS and 1\% Penicillin/Streptomycin under a humidified environment of $5 \% \mathrm{CO}_{2} / 95 \% \mathrm{O}_{2}$ incubator at $37^{\circ} \mathrm{C} \cdot \mathrm{PrP}^{\mathrm{C}}$ WT or KO cells (HW8-1 and $\mathrm{Hpl3-4}$, respectively) established from the primary cultured hippocampal neuron of Prnp ${ }^{+/+}$and Prnp ${ }^{-/-}$mice [27] were grown in exosome-depleted medium composed of 89\% DMEM, $10 \%$ FBS and 1\% Penicillin/Streptomycin. Exosomes were prepared as previously described [20] with minor modifications. In brief, exosome-enriched media was fractionated by centrifugation $(200,000 \mathrm{~g} \times 2 \mathrm{~h})$ on a $5-$ $30 \%$ of opti-prep gradient (Axis-Shield) in a SW-41 rotor (Beckman Coulter). $1 \mathrm{ml}$ from each fraction was collected and diluted 1:10 with pre-cooled phosphatebuffered saline (PBS) and collected by centrifugation for $1 \mathrm{~h}$ at $100,000 \mathrm{~g}$. A portion of the resultant pellets were boiled in $2 \times$ sample buffer and used for Western blotting. Fractions enriched in exosomes were used for subsequent studies. The amount of exosomes used was expressed in terms of total protein which was determined using the Pierce BCA assay kit (Thermo Scientific).

All procedures for collection and usage of human CSF were approved by the Mater Misericordiae University Hospital Research Ethics committee, Ireland. CSF was obtained from a 61-year-old female and a 71-year-old male donors both of whom were healthy and cognitively normal. $10 \mathrm{ml}$ of CSF in total was taken by lumbar puncture from the L3/L4 interspace, and kept on ice. CSF was used to isolate exosomes within $2 \mathrm{~h}$ of collection, using the procedure described above.

\section{Western blotting}

Samples containing $A \beta$ were mixed with $4 \mathrm{X} \mathrm{NuPAGE}^{\bullet}$ LDS sample buffer and electrophoresed on $\mathrm{NuPAGE}^{\oplus}$ 4 - 12\% Bis-Tris gels (Life Technology). Proteins were transferred onto PVDF membrane (Millipore) and the membrane blocked using 5\% skim-milk solution was immunoblotted with the anti-A $\beta$ antibody, 6E10 (Covance). For detection of exosomal proteins, samples were boiled after being mixed with $5 \mathrm{X}$ sample buffer, then electrophoresed on $10 \%$ polyacrylamide SDS gels, transferred onto PVDF membrane and finally immunoblotted with antibodies against Alix (BD Bioscience), Flotillin-1 (BD Bioscience), $\operatorname{PrP}^{\mathrm{C}}$ (ICSM-35, D-Gen), CD81 (Santa Cruz Biotechnology) or $\beta$-actin (Sigma). Immunoreactive bands were visualized using horseradish peroxidase-conjugated goat anti-mouse IgG secondary antibody (1:3000) (Signalway Antibody) and images were collected by Las-4000 (Fujifilm Life Science). The western blot images were analyzed using Image J software $(\mathrm{NIH})$.

\section{Atomic force microscopy (AFM)}

$10 \mu \mathrm{l}$ of $10 \mu \mathrm{M}$ ADDLs in PBS was incubated on freshly cleaved mica for $1 \mathrm{~min}$. The mica was washed twice with $100 \mu \mathrm{l}$ of deionized water and dried under a gentle stream of $\mathrm{N}_{2}$ gas. Tapping mode AFM imaging was performed in air using Multimode/Nanoscope IIIa (Digital instruments) equipped with a J-scanner. The images were taken with a TESP cantilever (Veeco) at a sample rate of $0.85 \mathrm{~Hz}$. Section analysis (Nanoscope V) was employed to measure the z-height of distinct globules $(>50)$ and the $z$-height was used as a representative value for the size of $A \beta$ oligomers [19].

\section{Electron microscopy (EM)}

$5 \mu \mathrm{l}$ drops of exosomes $(50 \mu \mathrm{g} / \mathrm{ml})$ were loaded onto carbon-coated $200 \mu \mathrm{m}$ copper grids and incubated for 1 min. The samples were then stained with $2 \%$ uranyl acetate for $2 \mathrm{~min}$, and excess solution carefully removed and the grid left to air dry. Images were captured using an electron microscope (JEOL) operated at $100 \mathrm{kV}$.

\section{Dynamic light scattering (DLS) spectroscopy}

The sizes of exosomes $(10 \mu \mathrm{g}$ in $100 \mu \mathrm{l})$ or ADDLs $(10 \mu \mathrm{M}$ in $100 \mu \mathrm{l}$ ) were measured by DLS performed with Zetasizer Nanoseries instrument (Malvern Nano-Zetasizer). The mean values of particle sizes were obtained from more than 3 independent preparations. 


\section{in vivo electrophysiology and i.c.v. infusion}

Electrodes were made and implanted in anaesthetized animals as described previously [6]. Briefly, twisted-wire bipolar electrodes were constructed with Teflon-coated tungsten wires $(62.5 \mu \mathrm{m}$ inner core diameter, $75 \mu \mathrm{m}$ external diameter, A-M Systems). Field excitatory postsynaptic potentials (fEPSPs) were recorded from the stratum radiatum of the CA1 area of the right dorsal hippocampus in response to stimulation of the ipsilateral Schaffer collateral-commissural pathway. Electrode implantation sites were identified using stereotaxic coordinates relative to bregma, with the recording site located $3.4 \mathrm{~mm}$ posterior to bregma and $2.5 \mathrm{~mm}$ right of midline, and the stimulating electrode located $4.2 \mathrm{~mm}$ posterior to bregma and $3.8 \mathrm{~mm}$ right of midline. The optimal depth of the electrodes was determined using electrophysiological criteria and verified post-mortem. Test fEPSPs were evoked at a frequency of $0.033 \mathrm{~Hz}$ at the stimulation intensities adjusted to elicit fEPSP amplitudes of 40 - $50 \%$ of maximum. The high-frequency stimulation (HFS) protocol for inducing LTP consisted of 10 bursts of 20 stimuli with an inter-stimulus interval of $5 \mathrm{~ms}(200 \mathrm{~Hz})$, and an interburst interval of $2 \mathrm{sec}$. The intensity was increased so as to give $75 \%$ of maximum amplitudes of fEPSPs during the HFS. The weak HFS consisted of 10 bursts of 10 stimuli with an inter-stimulus interval of $10 \mathrm{~ms}(100 \mathrm{~Hz})$, and an inter-burst interval of $2 \mathrm{sec}$. The initial slopes of fEPSPs were measured and the average of ten sweeps was plotted. Unless otherwise specified, fEPSP slopes (\% Baseline) indicate the mean slopes between 170 - 180 min after HFS in each condition. To infuse samples, a stainless-steel guide cannula (22 gauge, $0.7 \mathrm{~mm}$ outer diameter, $13 \mathrm{~mm}$ length) was implanted above the right lateral ventricle $(1 \mathrm{~mm}$ lateral to the midline and $4 \mathrm{~mm}$ below the surface of the dura) just prior to electrode implantation. The placement of the cannula was verified post-mortem with i.c.v. infusion of Indian Blue ink dye.

\section{Binding assays between ADDLs and exosomes}

ADDLs were centrifuged for $1 \mathrm{~h}$ at 100,000 g prior to incubation with exosomes. The supernatant contained more than $95 \%$ of the starting peptide. $1 \mu \mathrm{g}$ of this ADDL supernatant was then added to identical volumes of purified trypsinized or mock-trypsinized exosomes $(160 \mu \mathrm{g})$ and incubated at $37^{\circ} \mathrm{C}$ for $30 \mathrm{~min}$ in $10 \mathrm{ml}$ PBS. Thereafter, exosomes were separated from the unbound $\mathrm{A} \beta$ by centrifuging for $1 \mathrm{~h}$ at $100,000 \mathrm{~g}$. The exosome pellet was dissolved in $2 \times$ sample buffer and $25 \%$ of the mixture used for Western blotting for exosome-bound A $\beta .25 \%$ of the supernatant resulted from 100,000 g centrifugation was collected and used for immunoprecipitation with 6E10/Western blotting for exosome-unbound $\mathrm{A} \beta$. Mean \% of 12 and $16 \mathrm{kDa} \mathrm{A} \beta$ bound to exosomes
(P) relative to total $\sim 12$ and $16 \mathrm{kDa} A \beta(\mathrm{P}+\mathrm{S})$ was used for the presentation with bar graph.

\section{Limited trypsinization for surface proteins of exosomes}

Exosomes $(0.5 \mathrm{mg} / \mathrm{ml})$ were incubated with trypsin $(1 \mathrm{mg} / \mathrm{ml}$, Sigma) for $30 \mathrm{~min}$ at $37^{\circ} \mathrm{C}$ and the reaction was stopped by addition of a serine protease inhibitor Pefabloc $\mathrm{SC}^{\mathrm{m}}$ ( $4 \mathrm{mg} / \mathrm{ml}$, Sigma). After this treatment, exosomes were re-isolated by density gradient centrifugation (as described in the procedures for exosomes isolation). The effect of trypsin on surface and luminal proteins was verified by assessment of trypsinized- and mock-trypsinized exosomes with antibodies against $\operatorname{PrP}^{\mathrm{C}}, \mathrm{CD} 81$ (exosomal surface proteins) or Alix (luminal protein).

\section{Immunoprecipitation of exosomes}

Exosomes were incubated with anti-Flotillin-1 antibody $(8 \mu \mathrm{l})$ and pre-washed Protein A/G agarose bead (Calbiochem) at $4^{\circ} \mathrm{C}$ for $6 \mathrm{~h}$. The resulting precipitates were washed with PBS and $25 \%$ of each sample was used for western blotting.

\section{AD brain extracts}

Human tissue was obtained and used in accordance with local IRB guidelines. A sample of temporal cortex from a 92-year-old woman with a history of dementia and confirmed $\mathrm{AD}$ pathology was used to prepare water-soluble extracts and the extracts were examined for the presence of $\mathrm{A} \beta$ as described previously [6]. Briefly, a $\sim 2 \mathrm{~g}$ cube of frozen tissue was thawed on ice, gray matter isolated, chopped into small pieces with a razor blade and then homogenized in 5 volumes of ice-cold $20 \mathrm{mM}$ Tris- $\mathrm{HCl}$, $\mathrm{pH}$ 7.4, containing $150 \mathrm{mM} \mathrm{NaCl}$ (TBS) with 25 strokes of a Dounce homogenizer (Fisher). The water-soluble fraction was separated from the insoluble fraction by centrifugation at $91,000 \mathrm{~g}$ and $4^{\circ} \mathrm{C}$ in a TLA 55 rotor (Beckman Coulter) for $78 \mathrm{~min}$ and the supernatant was used for the subsequent studies. To eliminate lowmolecular-weight bioactive molecules and drugs, the supernatant was exchanged into sterile $50 \mathrm{mM}$ ammonium acetate, $\mathrm{pH} 8.5$ using a $5 \mathrm{ml} \mathrm{Hi}$-trap desalting column (GE Healthcare Bio-Sciences). Thereafter the extracts were divided into 2 parts: one aliquot was immunodepleted $\left(A D-A \beta^{-}\right)$of $A \beta$ by 3 rounds of $12 \mathrm{~h}$ incubations with the anti-A $\beta$ antibody, AW7 [55], and protein $A$ at $4{ }^{\circ} \mathrm{C}$. The second portion was treated identically, but pre-immune serum was used instead of AW7 anti-A $\beta$ antiserum and so produced a "mock"-immunodepleted samples $\left(\mathrm{AD}-\mathrm{A} \beta^{+}\right)$. The amount and form of $A \beta$ was analyzed in duplicate $0.3 \mathrm{ml}$ samples by immunoprecipitated with AW7 at a dilution of 1:80 and by western blotting using a combination of the C-terminal monoclonal antibodies, 2G3 and 21F12 (each at a concentration of $1 \mu \mathrm{g} / \mathrm{ml})$. Detection was achieved using fluorochrome-coupled anti-mouse secondary antibody 
(1:2500) (Rockland). Images were collected by scanning at $800 \mathrm{~nm}$ at a resolution of $169 \mu \mathrm{m}$ using a Li-COR Odyssey near infrared imaging system (Li-COR Biosciences). $A \beta$ present in the immunoprecipitates were quantified by references of known amounts of synthetic $A \beta_{1-42}$ loadings (2, 5, 10 ng per well) [55].

\section{Statistical analysis}

LTP was expressed as mean \pm SEM\% of baseline slopes of fEPSPs recorded over at least a 30 min baseline period. Statistical comparisons used paired Student t-tests to compare within single groups of animals for baseline or LTP results whereas unpaired t-tests were employed to compare the LTP between two groups. In the case of multiple comparisons, one-way ANOVA with post hoc Tukey test was used. The results from dynamic light scattering or immunoblots were expressed as mean \pm SEM \% and compared with Mann-Whitney $U$ test. Statistical significance between groups is expressed as N.S., not significant; *, $P<0.05$; **, $P<0.01$; or ${ }^{* * * *,}, P<0.001$.

\section{Additional file}

Additional file 1: Figure S1. Exosomes neutralize synaptic-plasticitydisrupting activity of $A \beta$ assemblies in vivo.

\section{Abbreviations}

AD: Alzheimer's disease; A $\beta$ : Amyloid $\beta$-protein; LTP: Long-term potentiation; ADDL: A $\beta$-derived diffusible ligand; $\operatorname{PrP}^{C}$ : Cellular prion proteins; i.c. v:: Intracerebroventricularly; CSF: Cerebrospinal fluid; DLS: Dynamic light scattering; $\mathrm{R}_{\text {H: }}$ Hydrodynamic radii; AFM: Atomic force microscopy; HFS: High-frequency stimulation; IDE: Insulin degrading enzyme; WT: Wild-type; KO: Knock-out; PBS: Phosphate-buffered saline; EM: Electron microscopy; fEPSP: Field excitatory postsynaptic potential.

\section{Competing interests}

The authors declare that they have no competing interests.

\begin{abstract}
Authors' contributions
KA, MJR and J-HK conceived the study. KA, MJR, DMW and J-HK designed the research. $\mathrm{KA}$ and $\mathrm{IK}$ performed and analyzed in vivo electrophysiology experiments. KA, IK, YK, JHJ, GMF, JWP and T-WK performed and analyzed in vitro experiments with ADDLs and exosomes. IK, AJM, DK, STO, TL and CAL isolated and characterized human brain extracts and CSF. KA, DMW, MJR and J-HK wrote the paper. All authors read and approved the final manuscript.
\end{abstract}

\section{Acknowledgements}

We thank T. Onodera (University of Tokyo) for providing WT and Prnp KO cell lines. We also like to thank Craig H. Bailey (Columbia University) for comments over previous versions of this manuscript. This work was supported by the Cure Alzheimer Fund to D.M.W., Science Foundation Ireland, the Health Research Board of Ireland and the European Union Seventh Framework Programme 528 (Grant Agreement MEMOLOAD 201159) to MJR, the Health Research Board of Ireland to I.K., and grants from Korea Healthcare technology R\&D Project, Ministry of Health \& Welfare (A0920581113-0000300 and A111284) and National Research Foundation of Korea (2011-0000835), Republic of Korea to J.-H.K.

\section{Author details}

${ }^{1}$ Department of Life Sciences, Pohang University of Science and Technology (POSTECH), Pohang, Gyungbuk 790-784, Korea. ${ }^{2}$ Department of Pharmacology and Therapeutics, and Institute of Neuroscience,
Biotechnology Building, Trinity College, Dublin 2, Ireland. ${ }^{3}$ School of Interdisciplinary Bioscience and Bioengineering, Pohang University of Science and Technology (POSTECH), Pohang, Gyungbuk 790-784, Korea. ${ }^{4}$ Laboratory for Neurodegenerative Research, Center for Neurologic Diseases, Brigham \& Women's Hospital, Harvard Institute of Medicine, 77 Avenue Louis Pasteur, Boston, MA 02115, USA. 'Laboratory for Neurodegenerative Research, Conway Institute of Biomolecular and Biomedical Research, University College Dublin, Dublin 4, Ireland. ${ }^{6}$ Dublin Neurological Institute at the Mater Misericordiae University Hospital, 57 Eccles Street, Dublin 7, Ireland. ${ }^{7}$ Department of Pathology and Cell Biology, Taub Institute for Research on Alzheimer's Disease and the Aging Brain, Columbia University, New York, NY 10032, USA.

Received: 23 September 2013 Accepted: 31 October 2013

Published: 13 November 2013

\section{References}

1. Selkoe DJ: Resolving controversies on the path to Alzheimer's therapeutics. Nat Med 2011, 17:1060-1065.

2. Selkoe DJ: Alzheimer's disease is a synaptic failure. Science 2002, 298:789-791.

3. Hardy J, Selkoe DJ: The amyloid hypothesis of Alzheimer's disease: progress and problems on the road to therapeutics. Science 2002, 297:353-356.

4. Benilova I, Karran E, De Strooper B: The toxic Abeta oligomer and Alzheimer's disease: an emperor in need of clothes. Nat Neurosci 2012, 15:349-357.

5. Lambert MP, Barlow AK, Chromy BA, Edwards C, Freed R, Liosatos M, Morgan TE, Rozovsky I, Trommer B, Viola KL, et al: Diffusible, nonfibrillar ligands derived from Abeta1-42 are potent central nervous system neurotoxins. Proc Natl Acad Sci USA 1998, 95:6448-6453.

6. Freir DB, Nicoll AJ, Klyubin I, Panico S, Mc Donald JM, Risse E, Asante EA, Farrow MA, Sessions RB, Saibil HR, et al: Interaction between prion protein and toxic amyloid beta assemblies can be therapeutically targeted at multiple sites. Nat Commun 2011, 2:336.

7. Lauren J, Gimbel DA, Nygaard HB, Gilbert JW, Strittmatter SM: Cellular prion protein mediates impairment of synaptic plasticity by amyloid-beta oligomers. Nature 2009, 457:1128-1132.

8. Yaar M, Zhai S, Pilch PF, Doyle SM, Eisenhauer PB, Fine RE, Gilchrest BA Binding of beta-amyloid to the p75 neurotrophin receptor induces apoptosis. A possible mechanism for Alzheimer's disease. J Clin Invest 1997, 100:2333-2340.

9. Xie L, Helmerhorst E, Taddei K, Plewright B, Van Bronswijk W, Martins R: Alzheimer's beta-amyloid peptides compete for insulin binding to the insulin receptor. J Neurosci Off J Soc Neurosci 2002, 22:RC221.

10. Klyubin I, Walsh DM, Lemere CA, Cullen WK, Shankar GM, Betts V, Spooner ET, Jiang L, Anwyl R, Selkoe DJ, Rowan MJ: Amyloid beta protein immunotherapy neutralizes Abeta oligomers that disrupt synaptic plasticity in vivo. Nat Med 2005, 11:556-561.

11. Barry AE, Klyubin I, Mc Donald JM, Mably AJ, Farrell MA, Scott M, Walsh DM, Rowan MJ: Alzheimer's disease brain-derived amyloid-beta-mediated inhibition of LTP in vivo is prevented by immunotargeting cellular prion protein. J Neurosci 2011, 31:7259-7263.

12. Thery C, Zitvogel L, Amigorena S: Exosomes: composition, biogenesis and function. Nat Rev Immunol 2002, 2:569-579.

13. Bellingham SA, Guo BB, Coleman BM, Hill AF: Exosomes: vehicles for the transfer of toxic proteins associated with neurodegenerative diseases? Front Physiol 2012, 3:124.

14. Sharples RA, Vella L, Nisbet RM, Naylor R, Perez K, Barnham KJ, Masters CL, Hill AF: Inhibition of gamma-secretase causes increased secretion of amyloid precursor protein C-terminal fragments in association with exosomes. FASEB J 2008, 22:1469-1478.

15. Bulloj A, Leal MC, Xu H, Castano EM, Morelli L: Insulin-degrading enzyme sorting in exosomes: a secretory pathway for a key brain amyloid-beta degrading protease. J Alzheimers Dis 2010, 19:79-95.

16. Yuyama K, Sun H, Mitsutake S, Igarashi Y: Sphingolipid-modulated exosome secretion promotes the clearance of amyloid-beta by microglia. J Biol Chem 2012, 287:10977-10989.

17. Okada T, Ikeda K, Wakabayashi M, Ogawa M, Matsuzaki K: Formation of toxic Abeta(1-40) fibrils on GM1 ganglioside-containing membranes 
mimicking lipid rafts: polymorphisms in Abeta(1-40) fibrils. $J \mathrm{Mol}$ Biol 2008, 382:1066-1074.

18. Sokolova TV, Zakharova IO, Furaev W, Rychkova MP, Avrova NF: Neuroprotective effect of ganglioside GM1 on the cytotoxic action of hydrogen peroxide and amyloid beta-peptide in PC12 cells. Neurochem Res 2007, 32:1302-1313.

19. Chromy BA, Nowak RJ, Lambert MP, Viola KL, Chang L, Velasco PT, Jones BW, Fernandez SJ, Lacor PN, Horowitz P, et al: Self-assembly of Abeta(1-42) into globular neurotoxins. Biochemistry 2003, 42:12749-12760.

20. Thery C, Amigorena S, Raposo G, Clayton A: Isolation and characterization of exosomes from cell culture supernatants and biological fluids. Curr Protoc Cell Biol 2006, 3:3-22.

21. Walsh DM, Klyubin I, Fadeeva JV, Cullen WK, Anwyl R, Wolfe MS, Rowan MJ, Selkoe DJ: Naturally secreted oligomers of amyloid beta protein potently inhibit hippocampal long-term potentiation in vivo. Nature 2002, 416:535-539.

22. Shankar GM, Li S, Mehta TH, Garcia-Munoz A, Shepardson NE, Smith I, Brett FM, Farrell MA, Rowan MJ, Lemere CA, et al: Amyloid-beta protein dimers isolated directly from Alzheimer's brains impair synaptic plasticity and memory. Nat Med 2008, 14:837-842.

23. Selkoe DJ: Clearing the brain's amyloid cobwebs. Neuron 2001, 32:177-180.

24. Velayos JL, Irujo A, Cuadrado-Tejedor M, Paternain B, Moleres FJ, Ferrer V: The cellular prion protein and its role in Alzheimer disease. Prion 2009, 3:110-117.

25. Vella LJ, Greenwood DL, Cappai R, Scheerlinck JP, Hill AF: Enrichment of prion protein in exosomes derived from ovine cerebral spinal fluid. Vet Immunol Immunopathol 2008, 124:385-393.

26. Vella LJ, Sharples RA, Lawson VA, Masters CL, Cappai R, Hill AF: Packaging of prions into exosomes is associated with a novel pathway of PrP processing. J Pathol 2007, 211:582-590.

27. Kuwahara C, Takeuchi AM, Nishimura T, Haraguchi K, Kubosaki A, Matsumoto Y, Saeki K, Matsumoto Y, Yokoyama T, Itohara S, Onodera T: Prions prevent neuronal cell-line death. Nature 1999, 400:225-226.

28. Inouye $\mathrm{H}$, Gleason KA, Zhang D, Decatur SM, Kirschner DA: Differentia effects of Phe19 and Phe20 on fibril formation by amyloidogenic peptide A beta 16-22 (Ac-KLVFFAE-NH2). Proteins 2010, 78:2306-2321.

29. Alvarez-Erviti L, Seow Y, Schapira AH, Gardiner C, Sargent IL, Wood MJ, Cooper JM: Lysosomal dysfunction increases exosome-mediated alpha-synuclein release and transmission. Neurobiol Dis 2011, 42:360-367.

30. Ghidoni R, Benussi L, Binetti G: Exosomes: the Trojan horses of neurodegeneration. Med Hypotheses 2008, 70:1226-1227.

31. Alais S, Simoes S, Baas D, Lehmann S, Raposo G, Darlix JL, Leblanc P: Mouse neuroblastoma cells release prion infectivity associated with exosomal vesicles. Bio/ Cell 2008, 100:603-615.

32. Yuyama K, Yamamoto N, Yanagisawa K: Accelerated release of exosomeassociated GM1 ganglioside (GM1) by endocytic pathway abnormality: another putative pathway for GM1-induced amyloid fibril formation. J Neurochem 2008, 105:217-224.

33. Tamboli IY, Barth E, Christian L, Siepmann M, Kumar S, Singh S, Tolksdorf K, Heneka MT, Lutjohann D, Wunderlich P, Walter J: Statins promote the degradation of extracellular amyloid \{beta\}-peptide by microglia via stimulation of exosome-associated insulin-degrading enzyme (IDE) secretion. J Biol Chem 2010, 285:37405-37414

34. Cullen WK, Suh YH, Anwyl R, Rowan MJ: Block of LTP in rat hippocampus in vivo by beta-amyloid precursor protein fragments. Neuroreport 1997, 8:3213-3217.

35. Cleary JP, Walsh DM, Hofmeister JJ, Shankar GM, Kuskowski MA, Selkoe DJ, Ashe $\mathrm{KH}$ : Natural oligomers of the amyloid-beta protein specifically disrupt cognitive function. Nat Neurosci 2005, 8:79-84.

36. Klyubin I, Betts V, Welzel AT, Blennow K, Zetterberg H, Wallin A, Lemere CA Cullen WK, Peng Y, Wisniewski T, et al: Amyloid beta protein dimer-containing human CSF disrupts synaptic plasticity: prevention by systemic passive immunization. The Journal of Neuroscience: the Official Journal of the Society for Neuroscience 2008, 28:4231-4237.

37. Townsend M, Shankar GM, Mehta T, Walsh DM, Selkoe DJ: Effects of secreted oligomers of amyloid beta-protein on hippocampal synaptic plasticity: a potent role for trimers. J Physiol 2006, 572:477-492.

38. Puzzo D, Privitera L, Leznik E, Fa M, Staniszewski A, Palmeri A, Arancio O: Picomolar amyloid-beta positively modulates synaptic plasticity and memory in hippocampus. J Neurosci Off J Soc Neurosci 2008,

28:14537-14545.
39. Giuffrida ML, Caraci F, Pignataro B, Cataldo S, De Bona P, Bruno V, Molinaro G, Pappalardo G, Messina A, Palmigiano A, et al: Beta-amyloid monomers are neuroprotective. J Neurosci Off J Soc Neurosci 2009, 29:10582-10587.

40. Balducci C, Beeg M, Stravalaci M, Bastone A, Sclip A, Biasini E, Tapella L, Colombo L, Manzoni C, Borsello T, et al: Synthetic amyloid-beta oligomers impair long-term memory independently of cellular prion protein. ProC Natl Acad Sci USA 2010, 107:2295-2300.

41. Gimbel DA, Nygaard HB, Coffey EE, Gunther EC, Lauren J, Gimbel ZA, Strittmatter SM: Memory impairment in transgenic Alzheimer mice requires cellular prion protein. J Neurosci Off J Soc Neurosci 2010, 30:6367-6374

42. Kessels HW, Nguyen LN, Nabavi S, Malinow R: The prion protein as a receptor for amyloid-beta. Nature 2010, 466:E3-E4. discussion E4-5.

43. Zou WQ, Xiao X, Yuan J, Puoti G, Fujioka H, Wang X, Richardson S, Zhou X, Zou R, Li S, et al: Amyloid-beta42 interacts mainly with insoluble prion protein in the Alzheimer brain. J Biol Chem 2011, 286:15095-15105.

44. Larson M, Sherman MA, Amar F, Nuvolone M, Schneider JA, Bennett DA, Aguzzi A, Lesne SE: The Complex PrPc-Fyn Couples Human Oligomeric Abeta with Pathological Tau Changes in Alzheimer's Disease. J Neurosci Off J Soc Neurosci 2012, 32:16857-16871.

45. Chen S, Yadav SP, Surewicz WK: Interaction between human prion protein and amyloid-beta (Abeta) oligomers: role OF N-terminal residues. J Biol Chem 2010, 285:26377-26383.

46. Klyubin I, Cullen WK, Hu NW, Rowan MJ: Alzheimer's disease Abeta assemblies mediating rapid disruption of synaptic plasticity and memory. Mol Brain 2012, 5:25.

47. Cirrito JR, Kang JE, Lee J, Stewart FR, Verges DK, Silverio LM, Bu G, Mennerick S, Holtzman DM: Endocytosis is required for synaptic activity-dependent release of amyloid-beta in vivo. Neuron 2008, 58:42-51.

48. Street JM, Barran PE, Mackay CL, Weidt S, Balmforth C, Walsh TS, Chalmers RT, Webb DJ, Dear JW: Identification and proteomic profiling of exosomes in human cerebrospinal fluid. J Transl Med 2012, 10:5.

49. Tauro BJ, Greening DW, Mathias RA, Ji H, Mathivanan S, Scott AM, Simpson RJ: Comparison of ultracentrifugation, density gradient separation, and immunoaffinity capture methods for isolating human colon cancer cell line LIM1863-derived exosomes. Methods 2012, 56:293-304.

50. Lai YL, Smith PM, Lamm WJ, Hildebrandt J: Sampling and analysis of cerebrospinal fluid for chronic studies in awake rats. J Appl Physiol 1983, 54:1754-1757.

51. Gutwein P, Stoeck A, Riedle S, Gast D, Runz S, Condon TP, Marme A, Phong MC, Linderkamp O, Skorokhod A, Altevogt P: Cleavage of L1 in exosomes and apoptotic membrane vesicles released from ovarian carcinoma cells. Clin Cancer Res Off J Am Assoc Cancer Res 2005, 11:2492-2501.

52. Rajendran L, Honsho M, Zahn TR, Keller P, Geiger KD, Verkade P, Simons K Alzheimer's disease beta-amyloid peptides are released in association with exosomes. Proc Natl Acad Sci USA 2006, 103:11172-11177.

53. Lachenal G, Pernet-Gallay K, Chivet M, Hemming FJ, Belly A, Bodon G, Blot B, Haase G, Goldberg Y, Sadoul R: Release of exosomes from differentiated neurons and its regulation by synaptic glutamatergic activity. Mo/ Cell Neurosci 2011, 46:409-418.

54. Dolev I, Fogel H, Milshtein H, Berdichevsky Y, Lipstein N, Brose N, Gazit N, Slutsky I: Spike bursts increase amyloid-beta $40 / 42$ ratio by inducing a presenilin-1 conformational change. Nat Neurosci 2013, 16:587-595.

55. McDonald JM, Cairns NJ, Taylor-Reinwald L, Holtzman D, Walsh DM: The levels of water-soluble and triton-soluble Abeta are increased in Alzheimer's disease brain. Brain Res 2012, 1450:138-147.

doi:10.1186/1756-6606-6-47

Cite this article as: An et al:: Exosomes neutralize synaptic-plasticitydisrupting activity of $A \beta$ assemblies in vivo. Molecular Brain 2013 6:47. 